Article

\title{
One Health Approach for combating Antimicrobial Resistance in Animals
}

\section{Chung-Ming Chang ${ }^{1 *}$ Ramendra Pati Pandey ${ }^{2 *}$, Riya Mukherjee ${ }^{1,2}$}

${ }^{1}$ Master \& Ph.D. program in Biotechnology Industry, Chang Gung University, No.259, Wenhua 1st Rd., Guishan Dist. Taoyuan City 33302, Taiwan (R.O.C.); cmchang@mail.cgu.edu.tw (C.M.C.)

${ }^{2}$ Centre for Drug Design Discovery and Development (C4D), SRM University, Delhi-NCR, Rajiv Gandhi Education City, Sonepat - 131 029, Haryana, India

\section{*Corresponding authors and equal contribution}

Chung-Ming Chang*, Master \& Ph.D. program in Biotechnology Industry, Chang Gung University, No.259, Wenhua 1st Rd., Guishan Dist. Taoyuan City 33302, Taiwan (R.O.C.), cmchang@mail.cgu.edu.tw (C.M.C.);

\section{Abstract \\ Background}

Antimicrobial resistance (AMR) is an increasing hazard to human and animal health that necessitates international response. Surveillance of AMR, on the other hand, is at best in its infancy, and the current evidence base for informing policymakers is geographically disparate. All of the isolates had high rates of AMR to medicines that are critical/highly important in human and animal medicine.

\section{Methods}

Type of poultry production, nation location, AMR testing methodologies, sample year and One Health Approach implementation were analyzed. Data on the prevalence of AMR (Antimicrobial Resistance) by country has been compiled, as well as the emergence of the One Health Approach to aid in the resolution of this global challenge.

\section{Findings}


Our findings show that AMR, including MDR, is common in coli, Salmonella spp., commonly found in poultry. The study promotes the development of national policies, programs, and additional research based on a "One Health" approach that helps humans and animals, as well as the environment.

\section{Conclusion}

Our article concludes that MDR foodborne bacteria are widely found in poultry farms in rural areas or poultry-retail stores in urban areas, potentially posing a hazard to human/animal or environmental health as well as food security. As a result, we should advocate the regulation of antimicrobial use in food animals, specifically the establishment of national policies that take a "One health" perspective to human/animal health.

Keywords: One Health Strategies, Antimicrobial Resistance, Salmonella isolates, Poultry Farms, Turkey Poults. 


\section{Introduction}

Antimicrobial resistance (AMR) is a huge problem for people, animals, and the environment, with the developing world bearing the brunt of it. It necessitates global as well as local action. Over the last few decades, poultry industry has under gone various transitions as the whole industry has moved from its backyard extensive activities to its rising commercial progress. It has become one of the fastest growing sectors globally. All the countries globally are constantly increasing the production of chickens bred and eggs for acquiring business benefits. India is the world's thirdlargest egg producer, trailing only China and the United States, and the fourth-largest chicken producer, trailing only China, Brazil, and the United States. (1)

The domestic production of poultry products in Taiwan meets about $80 \%$ of demand. The two biggest providers of chicken imports to Taiwan are the United States and Canada, with the United States accounting for over $90 \%$ of the import market in recent years. (2) In 2018, Africa produced 5.7 million tonnes of chicken meat, up 4.2 percent from the previous year. Between 2013 and 2018, the overall output volume increased at an annual rate of 2.4 percent on average. South Africa (1.8 million tonnes) produced the most chicken on the continent in 2018, followed by Egypt (1.1 million tonnes) and Morocco (720,000 tonnes), accounting for 62 percent of overall production. (3) The expansion of the chicken business improves both the economy and food security worldwide.

However, it has resulted in a serious public and environmental health issue: the spread of antibiotic resistance (AMR). Poultry flocks are frequently reared under harsh conditions, with huge doses of antimicrobials used to prevent and treat disease as well as promote growth. Antimicrobialresistant poultry infections can cause treatment failure, resulting in financial losses, but they can also be a source of resistant bacteria/genes (including zoonotic germs) that can be harmful to humans. Antimicrobial resistance (AMR) is a major public health concern around the world. A substantial amount of research has accumulated in recent years indicating the contribution of antibiotic usage (AMU) and AMR from animals to the overall burden of AMR. Excessive usage of antimicrobials in food animal production is a contributing issue. Due to the expansion of farming techniques in most of the developing countries, the scale of antimicrobials usage is likely to expand significantly in the future years. (4) Large portion our understanding and assumptions about 
the prevalence and evolution of AMR in animal production systems are based on commensal bacteria like E. coli, Enterococcus spp., and Staphylococcus aureus, as well as foodborne zoonotic pathogens like non-typhoidal Salmonella (NTS) and Campylobacter spp. (5) Poultry farming is one of the most widely practiced food industries in the world. Chicken being the most widely farmed species, with over 90 billion tonnes of chicken meat produced each year. The main reasons for this are the low production costs and the lack of cultural and religious constraints on its use. In most countries, antimicrobials are used to raise poultry, usually through the oral route, with the goal of preventing and treating disease, as well as enhancing growth and production. (6)

Antimicrobials used indiscriminately in animal agriculture are likely to hasten the development of AMR in pathogens and commensal organisms. There are also human health concerns about the presence of antimicrobial residues in meat and eggs, in addition to the concerns raised by the emergence of AMR in bacteria from poultry production. Furthermore, AMR in poultry pathogens is anticipated to result in financial losses as a result of ineffective antimicrobials and the burden of untreated poultry disease. (7) (8)

We summarized the data on antimicrobial resistance genes gathered from poultry diseases in this research study piece. This will show the current state of the global poultry sector and serve as a benchmark against which country-specific data can be compared, as well as a driver for further isolation and AMR testing of poultry bacterial pathogens using harmonized methodology introducing the One Health Approach.

\section{Method}

We used the PubMed, Google Scholar, CDC (Centre for Disease Control) are the websites for searching the articles that provided their records on poultry industry and containing the term AMR (Antimicrobial Resistance) in combination with the poultry. The following data was compiled and analyzed from each article containing phenotypic data on AMR (Antimicrobial Resistance):

- Type of poultry production

- Nation location 


\section{- Sample year}

- AMR testing methodology (including interpretation criteria); phenotypic resistance data Agricultural intensification is expected to result in a 67 percent increase in antimicrobial usage by 2030, with Low-to middle income countries (LMICs) leading the way. China, for example, is predicted to consume $30 \%$ of all veterinary antimicrobials sold in 2030 , accounting for $50 \%$ of global pork output. Antibiotic use increased by more than 36\% in 71 countries between 2000 and 2010, with Brazil, Russia, India, China, and South Africa accounting for more than $75 \%$ of the rise. (9) Data on the prevalence of AMR (Antimicrobial Resistance) by country has been compiled, as well as the emergence of the One Health Approach to aid in the resolution of this global challenge.

\section{Data Analysis}

Poultry, one of the fastest-growing animals per capita, (figure 1) will continue to grow as countries transition from subsistence to intensive farming, which necessitates AMU (Antimicrobial Usage) on a regular basis. The prevalence of poultry is due to many fundamental characteristics: high energy uptake efficiency, great adaptability to environmental circumstances, smaller size of the body, and shortened life cycle. When compared to other terrestrial animals. (10) (11) (12) Galliformes (chickens, turkeys, quail, pheasants, grouse, guinea fowl), Anseriformes (ducks, geese, swans), Columbiformes (pigeons and doves), and Ratites (rats) make up the majority of poultry species (ostriches, emus). Poultry production is one of the world's fastest increasing per capita meats. The global poultry yearly growth rate has been $5 \%$ for the last half-century. In contrast, for beef, pig, and small ruminants, it was only 1.5 percent, 3.1 percent, and 1.7 percent, respectively. Chickens (Gallus gallus domesticus) account for $90 \%$ of global poultry output, with an estimated 23 billion chickens. (11) Individual investigations were tabulated to show the prevalence of resistance to certain antimicrobials. The phenotypic data on AMR (Antimicrobial Resistance) was studied for analyzing and the paper containing the data on MIC50 (or Minimum Inhibitory Concentration required to prevent the growth of $50 \%$ of organisms) was compiled for studies that used dilution methods, either as published or extrapolated from the MIC distribution through antimicrobial susceptibility tests. Furthermore, the approach of One Health protocols implemented in different countries were compiled in a tabular form for following up with the strategies in combating the 
antimicrobial resistance. This analyzing technique therefore helped in providing us with the emergence of frequently multi-resistant organisms among animals.

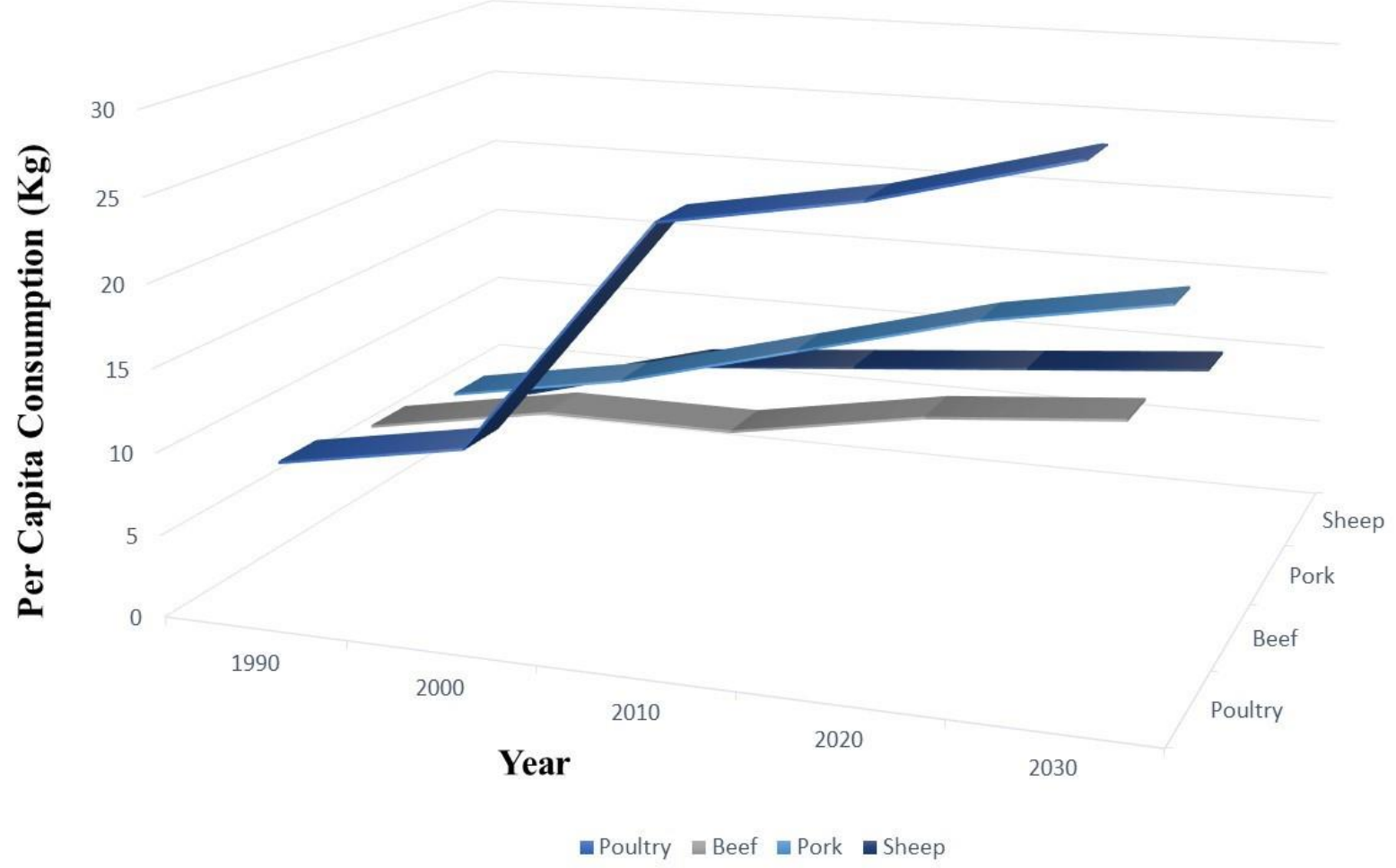

Figure 1. Data roughly summarized from OECD (Organization for Economic Co-operation and Development) meat consumption which provides a sharp increase in the poultry consumption in terms of per capita $(\mathrm{Kg})$ globally.

\section{Africa}

Ethiopia has approximately 56.87 million chickens, the majority of which are preserved in lowinput low-output village chicken production systems. Chicken provides an important source of income for poor smallholder households, in addition to eggs and meat. However, Ethiopia's annual per capita egg consumption of $0.5 \mathrm{~kg}$ is five times lower than the average of $2.3 \mathrm{~kg}$ per capita in other Sub-Saharan African countries. Despite having suitable phenotypic traits for Ethiopia's ecological, social, and cultural context, Ethiopian indigenous chickens cannot be produced and fill the national demand for chicken meat and eggs. (13) Farm hygiene, biosecurity, diagnostic capabilities, pathogen monitoring, tracing, and notification, as well as AMR, are not well developed in Ethiopia and uncontrolled antimicrobial use and misuse are frequent. As a result, the burden of 
diseases in poultry multiplication facilities in Ethiopia is unknown, posing a risk of infecting chicks if not treated properly. (14) (15) (16) Other than Ethiopia, other all regions of Africa have good percentage of AMU and AMR in animals. The (figure 2) describes the distribution of percentage of AMU and AMR. Salmonella is one of the key diseases wreaking havoc on the poultry business. According to a study conducted in Northern Ethiopia, Salmonella was found in 39.3 percent of native breeds and 29.2 percent of commercial varieties. (17) Salmonellosis has a significant economic impact on chicken production, resulting in 100\% morbidity, decreased production, and $20 \%$ death in infected flocks. One of the most common food-borne zoonotic pathogens is Salmonella. Another capacity of Salmonella that makes it difficult to eradicate is its ability to acquire antibiotic resistance (AMR). Because such resistant strains are typically untreatable with currently available antimicrobials, their emergence and dissemination among food animals is a life-threatening and global public-health concern. Between 2009 and 2015, 3544 avian pathogenic Escherichia coli strains were isolated from commercial broilers in South Africa and evaluated for sensitivity to eight antibiotic classes. (18)

\section{\% OF ANTIMICROBIAL RESISTANCE AND ANTIMICROBIAL USAGE}

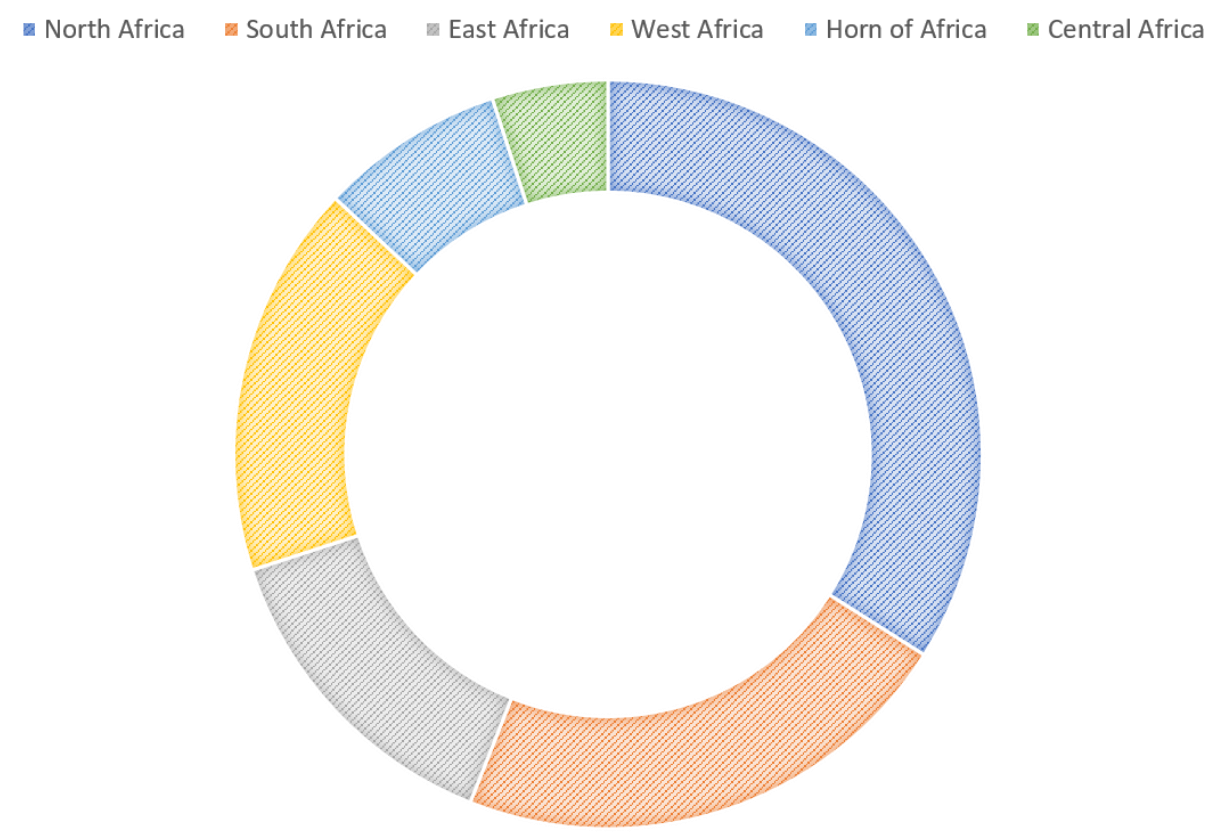

Figure 2. Distribution of percentage of antimicrobial resistance and antimicrobial usage in Africa. 
Asian Countries such as India and Taiwan are highly increasing their commercial ventures through the poultry industry. Antimicrobial resistance of Salmonella isolated from turkey farms in Taiwan has increased in recent years. 243 Salmonella strains were discovered from 2,040 samples (11.9 percent) from turkey farms over the last two years. Interestingly, the strains those were isolated through the study, among them a very high frequency of antimicrobial resistance has been observed. In addition to that the common resistant genes were found among the strains. (19) Similarly, in India a study has been done where 342 isolates of which 104 are Salmonella species were acquired from different sources like cecal and fecal samples of chicken collected from various states of India for a comparative study. High rates of AMR were accounted against the critical and very efficient drugs and a higher incidence of AMR was found in poultry-retail stores than on poultry-farms. Significantly, more than $90 \%$ of all isolates were MDR, and the pattern/prevalence of MDR varied significantly between poultry farms and poultry retail outlets. (20)

\section{Europe}

The S. Gallinarum and S. Pullorum were isolated from the poultry of Brazil. There were 32 S. Gallinarum and 18 S. Pullorum used in all. Septicemic infections are caused by these biovars, which have a significant fatality rate. Outbreaks are common over the world, resulting in losses due to the removal of affected flocks and treatments. Antimicrobial medicines are frequently used to prevent or cure gastrointestinal illnesses in chicken farms. The antimicrobial susceptibility of $50 S$. Gallinarum and S. Pullorum isolates from outbreaks that occurred between 1987 and 1991 and 2006 to 2013 was assessed in this study. When the susceptibility profiles were compared, it was shown that all of the isolates were susceptible to $\beta$-lactams. (21) Other EU member states have also accounted for the ill poultry handling which are responsible for spreading the resistant genes among the other domestic animals and humans as well.

\section{America}

Antibiotic usage in humans and animals is poorly regulated in Latin America (LA), and antibiotics are freely available over the counter without a prescription. AMR (Antimicrobial Resistance) has 
been related to rural areas in Latin America, in addition to metropolitan clinical settings. Smallscale animal farming is common in these areas, and animal excreta are a major source of fecal contamination in residential human environments. As a result, rural areas may be an essential ecosphere for the spread of AMR (Antimicrobial Resistance). However, AMR (Antimicrobial Resistance) transmission channels are not well documented in rural areas of low- and middle-income countries, particularly Latin American countries, and the evidence available is sparse.(22) (23) The available literature is scarce and sometimes lacks scientific rigor, offering inadequate information for an acceptable overview; and there is a scarcity of One Health research involving the human, animal, and environmental domains. (24)

\section{Pathogen Study}

Salmonella pullorum/gallinarum are biovars of Salmonella enterica subspecies enterica, which belongs to the Enterobacteriaceae family. They are the causative agents of pullorum illness (S. pullorum) and fowl typhoid (S. gallinarum), two septicemic diseases that are still prevalent in many parts of the world, despite the fact that they have been exterminated from poultry industry operations in many developed economies. 
Only these two serotypes can produce a substantial mortality rate in birds among the 2,700 serotypes. They can be passed down vertically from generation to generation as well as horizontally within a flock. Once the flock has been infected, the survivors will always be carriers. Because of these qualities, eradication is used as a regular control process in the commercial chicken meat sector around the world. When compared to broiler flocks, the prevalence of typhoid infection, which is mostly caused by Salmonella gallinarum, is much higher in layer chickens (eggs). The fundamental reason for this is a lack of adequate biosecurity. Most layer farms have varied ages, making allin-all-out control impossible, putting biosecurity at risk. It is impossible to eliminate the illness once it has been placed unless the entire farm is cleaned. (25) Several other pathogens have been identified through the screening of grey report that have emerged from extensive use of various

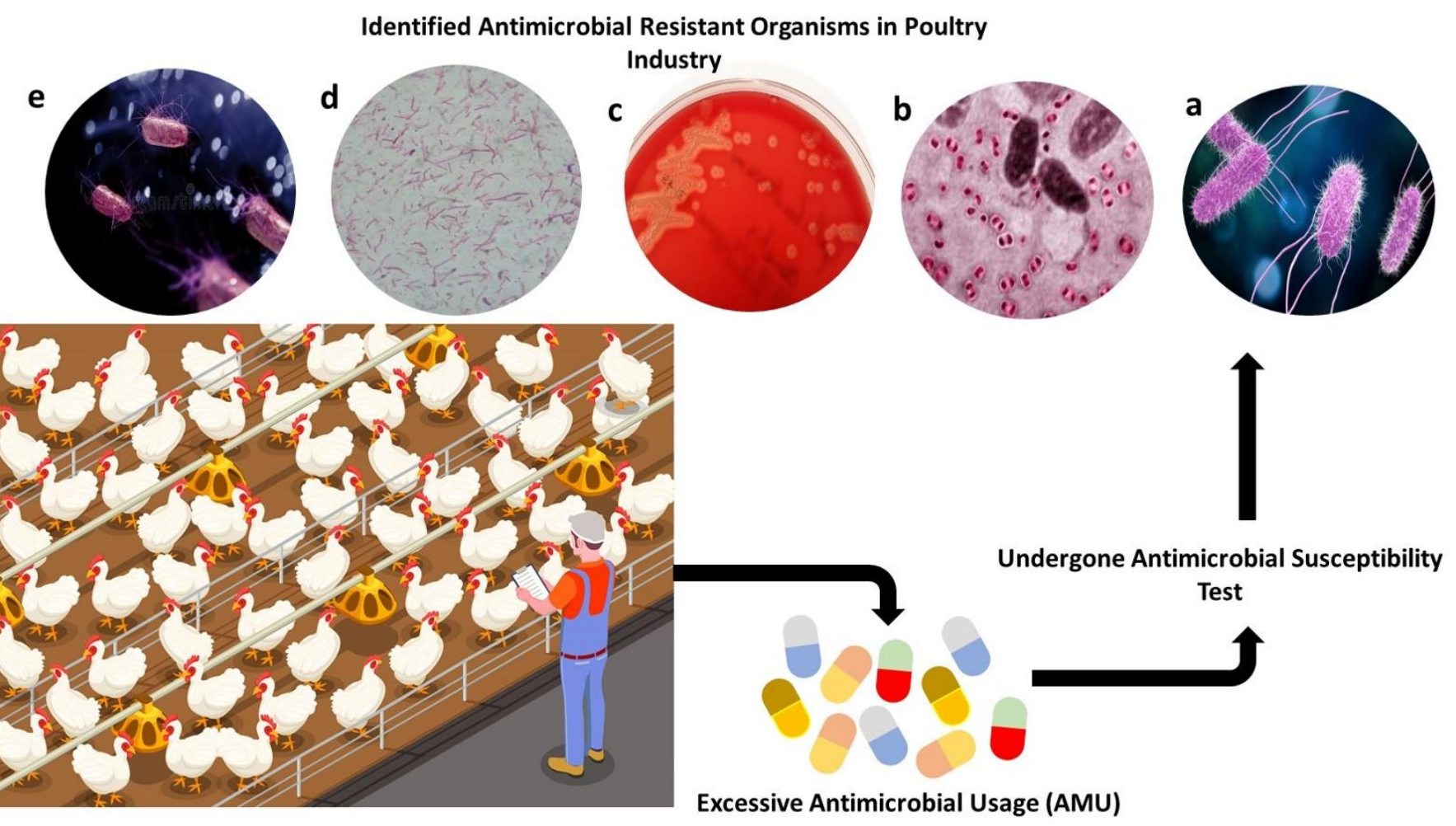

antimicrobials and has spread the antimicrobial resistance genes and organisms in the poultry industry. (Figure 3)

Figure 3. The figure illustrates the poultry farm getting affected with excessive antimicrobial usage which when undergone antimicrobial susceptibility test have resulted in identification of different organisms which were resistant to major group of antimicrobials. a) Salmonella sp. b) Pas- 
teurella multocida c) Gallibacterium anatis d) Avibacterium paragallinarum e) E.coli ; these are the organisms predominantly discovered to be resistant.

\section{Discussions and Results}

If countries are to make the best use of their clinical and veterinary facilities, they must have a deliberate political commitment to address AMR, including specific funding and the implementation of a fully interdisciplinary National Action Plan. With the majority of countries having "no capacity" for "AMR Surveillance," national and regional capacity must be established in order to achieve the necessary surveillance levels for critical human and animal pathogen AMRs. A progressive strategy should be followed to guarantee that this is sustainable and achievable.

Antimicrobial Susceptibility tests were performed in all the mentioned countries to find out the common antimicrobials used in poultry farm that are found to be resistant. Very popular antimicrobials such as ampicillin, cefoxitin, nalidixic acid, streptomycin, tetracycline, ciprofloxacin, and colistin are of great importance in human health as well. Excessive use of these antimicrobials in the poultry industry has led to the emergence of not only antimicrobial resistance among them but also high frequency of multi-drug resistance has been witnessed. This has successfully shown that the use of these antimicrobials among the humans for prolong has no longer in effect for preventing any disease specially food borne infections and diseases. The study has helped to identify that Salmonella sp. is predominant in poultry industry whose isolates can be responsible for numerous food borne diseases and are resistant to almost all critical and important antimicrobials. (Table 1)

Also, the respective continents and countries have started establishing and implementing laws for controlling the AMR through the One Health Approach. The goals of the One Health Approach can be the possible reasons for controlling the AMR through various surveillance, disease controlling protocols. (Table 1)

Table 1. Antimicrobial Susceptibility Test for identifying the Salmonella organism resistant to various antimicrobials globally.

\begin{tabular}{|c|c|c|c|c|c|}
\hline $\begin{array}{l}\text { Type of } \\
\text { Poultry }\end{array}$ & Continent & Organism & $\begin{array}{l}\text { Testing } \\
\text { Methodology }\end{array}$ & $\begin{array}{l}\text { Antimicrobial } \\
\text { Resistance }\end{array}$ & $\begin{array}{l}\text { One Health Ap- } \\
\text { proach }\end{array}$ \\
\hline
\end{tabular}




\begin{tabular}{|c|c|c|c|c|c|}
\hline Production & & & & & \\
\hline $\begin{array}{l}\text { Poultry } \\
\text { Chickens }\end{array}$ & $\begin{array}{l}\text { Africa } \\
\text { (Ethiopia) }\end{array}$ & $\begin{array}{l}\text { Salmonella } \\
\text { isolates }\end{array}$ & $\begin{array}{l}\text { Antimicrobial } \\
\text { Susceptibility } \\
\text { Test }\end{array}$ & $\begin{array}{l}-100 \% \text { Resistance } \\
\text { to Kanamycin } \\
-100 \% \text { Resistance } \\
\text { to sulfamethoxa- } \\
\text { zole- } \\
\text { trimethoprim. } \\
\text { - Resistance to } \\
\text { Ampicillin, cefox- } \\
\text { itin, nalidixic ac- } \\
\text { id, streptomycin, } \\
\text { tetracycline. }\end{array}$ & $\begin{array}{l}\text { Africa CDC has } \\
\text { incorporated } \\
\text { One Health Ap- } \\
\text { proach in com- } \\
\text { bating AMR. } \\
\text { Established in } \\
2018 .\end{array}$ \\
\hline $\begin{array}{l}\text { Turkey } \\
\text { Poults }\end{array}$ & $\begin{array}{l}\text { Asian } \\
\text { Countries } \\
\text { (Taiwan) }\end{array}$ & $\begin{array}{l}\text { Salmonella } \\
\text { isolates }\end{array}$ & $\begin{array}{l}\text { Antimicrobial } \\
\text { Susceptibility } \\
\text { Test }\end{array}$ & $\begin{array}{l}\text {-Resistance to } \\
\text { Florfenicol ap- } \\
\text { proximately } 97 \% \\
\text {-Resistance to } \\
\text { Ampicillin, sul- } \\
\text { famethoxazole- } \\
\text { trimethoprim, na- } \\
\text { lidixic acid, } \\
\text { Ciprofloxacin, } \\
\text { Colistin }\end{array}$ & $\begin{array}{l}\text { Strict legal } \\
\text { frameworks, pol- } \\
\text { icy and laws } \\
\text { such as antibiotic } \\
\text { stewardship, } \\
\text { check on the us- } \\
\text { age of antimi- } \\
\text { crobials, etc. are } \\
\text { being followed } \\
\text { in Taiwan for } \\
\text { keeping a check } \\
\text { on AMR records }\end{array}$ \\
\hline $\begin{array}{l}\text { Poultry farm } \\
\& \quad \text { Poultry } \\
\text { retail shops }\end{array}$ & $\begin{array}{l}\text { Asian } \\
\text { Countries } \\
\text { (India) }\end{array}$ & $\begin{array}{l}\text { Salmonella } \\
\text { isolates }\end{array}$ & $\begin{array}{l}\text { Antimicrobial } \\
\text { Susceptibility } \\
\text { Test }\end{array}$ & $\begin{array}{l}\text {-Resistance to } \\
\text { Amoxicillin, } \\
\text { Cefazolin, Ciprof- } \\
\text { loxacin, Strepto- } \\
\text { mycin, Colistin, } \\
\text { trimethoprim. }\end{array}$ & $\begin{array}{l}\text { Little attention is } \\
\text { paid but has re- } \\
\text { cently started } \\
\text { implementing } \\
\text { various laws for } \\
\text { establishing the } \\
\text { One Health Ap- } \\
\text { proach in the } \\
\text { country. }\end{array}$ \\
\hline $\begin{array}{l}\text { Poultry } \\
\text { Chickens }\end{array}$ & Europe & $\begin{array}{l}\text { Salmonella } \\
\text { isolates } \\
\text {-S. Galli- } \\
\text { narum } \\
\text { - S. Pullo- } \\
\text { rum }\end{array}$ & $\begin{array}{l}\text { Antimicrobial } \\
\text { Susceptibility } \\
\text { Test }\end{array}$ & $\begin{array}{l}\text {-Resistance to } \\
\text { Quinolones, Fluo- } \\
\text { roquinolones, } \\
\text { Tetracyclines }\end{array}$ & $\begin{array}{l}\text { Various One } \\
\text { Health Trainings } \\
\text { are being con- } \\
\text { ducted for prop- } \\
\text { er surveillance } \\
\text { and controlling } \\
\text { AMR in context } \\
\text { with One Health } \\
\text { Approach. }\end{array}$ \\
\hline Poultry & America & Salmonella & Antimicrobial & $-100 \%$ Resistance & Various training \\
\hline
\end{tabular}




\begin{tabular}{|c|c|c|c|c|c|}
\hline Farm & (Brazil) & isolates & $\begin{array}{l}\text { Susceptibility } \\
\text { Test }\end{array}$ & $\begin{array}{l}\text { to sulfamethoxa- } \\
\text { zole- } \\
\text { trimethoprim. } \\
\text { - Resistance to } \\
\text { Ampicillin, cefox- } \\
\text { itin, nalidixic ac- } \\
\text { id, streptomycin, } \\
\text { tetracycline. }\end{array}$ & $\begin{array}{l}\text { institutes for } \\
\text { One Health } \\
\text { strategies, laws } \\
\text { and legal plan- } \\
\text { ning are imple- } \\
\text { mented } \\
\text { throughout the } \\
\text { country strictly } \\
\text { for controlling } \\
\text { AMR with the } \\
\text { help of multidis- } \\
\text { ciplinary sectors. }\end{array}$ \\
\hline
\end{tabular}

\section{One Health Approach}

The term 'One Health' was first coined in 2003-2004, in response to the onset of severe acute respiratory syndrome (SARS) in early 2003 and the eventual spread of highly pathogenic avian influenza H5N1, as well as a set of strategic goals known as the 'Manhattan Principles,' formulated at a meeting of the Wildlife Conservation Society in 2004, which recognized the link between human and animal health and the threats that diseases pose to food supply chains. These precepts were a critical step toward acknowledging the critical importance of collaborative, cross-disciplinary approaches for responding to emerging and resurgent diseases, and in particular, for including wildlife health as an important component of global disease prevention, surveillance, control, and remediation.

Antimicrobial resistance (AMR) has received little consideration in the development of a "One Health" strategy. As a result, we analyze the amount of AMR and the dynamics/pattern of multidrug resistance using a multi-disciplinary approach. The study promotes the development of national policies, programs, and additional research based on a "One Health" approach that helps both humans and animals, as well as the environment.

The Africa Centres for Disease Control and Prevention (Africa CDC) takes a multidisciplinary, One Health approach to making Africa safer and healthier for people, animals, plants, and the environment. One Health Approach was incorporated into the Africa's CDC work process when the 
One Health strategy was established in the year 2018. Africa CDC understood the importance of One Health Approach in delivering effectively and efficiently the surveillance programme, disease prevention and control, policy making and public health emergency. (26)

Similarly, to address the growing threat posed by AMR, Taiwan's CDC established the National Antimicrobial Stewardship Program, established multi-channel surveillance on multidrugresistant organisms (MDROs), conducted hospital accreditation and hospital infection control inspections related to antimicrobial stewardship, carried out coordinated infection control interventions, and implemented appropriate use of antimicrobials.

Furthermore, the Taiwan CDC is proactive in developing relevant recommendations, e-learning materials, and antimicrobial and hand hygiene awareness campaigns to engage all people in the fight against AMR. (27)

Every country in the European region has or is preparing an AMR national action plan, which includes a variety of actions to help stop or at least limit the spread of this critical threat. The establishment of guidelines for medical experts on how to use antibiotics and which medications to use in certain scenarios could be one of these strategies. They could also include legislation regulating antibiotic sales and enhancing laboratory and surveillance system quality. Countries have been encouraged to embrace the One Health approach as an overall guiding principle in crafting their action plans. One Health plans make it easier to coordinate intersectoral efforts in accordance with national goals and policies.(28) Reduce needless antibiotic prescriptions and consumption in both the human and veterinary sectors, and use better cleanliness and vaccination to prevent infections in humans and animals in the first place. These planning are made by the officials under the One Health Approach for a better future.

However, in India little attention is given to this One Health Approach. Yet multiple national plans and legal frameworks are being announced in India from the government keeping the urge of One Health Approach in context with antimicrobial resistance, a very prominent threat globally. (29) (30) (31)

\section{Conclusion}


Our findings show that AMR is more common in Salmonella spp., poultry isolates, and that these bacteria are frequently multi-resistant to a variety of vital or extremely significant medications in human and veterinary medicine. Our findings suggest that MDR foodborne bacteria are widely found in poultry farms in rural areas or poultry-retail stores in urban areas, potentially posing a hazard to human/animal or environmental health as well as food security. As a result, we should advocate the regulation of antimicrobial use in food animals, specifically the establishment of national policies that take a "One health" perspective to human/animal health. As a result, we recommend that all farm attendants and visitors receive personal hygiene, biosafety, and farm biosecurity training, as well as education on zoonotic pathogens, restrictions on uncontrolled antimicrobial use, and the establishment of a standard pathogen and AMR monitoring system in poultry production maintain the One Health Strategies and laws. Overall, we believe that controlling Salmonella infections in poultry will be a significant step in reducing Salmonella infections in the general public.

\section{Acknowledgements}

This work was supported through both the industry-academia collaboration project, VtR IncCGU, R.O.C., project grant (SCRPD1L0221); and also the CGU project grant (UZRPD1L0011). 


\section{References}

1. Joshi M. One Health Poultry Hub [Internet]2019. Available from: https://www.onehealthpoultry.org/blog-posts/antimicrobial-resistance-in-indian-poultry-causeconcern-and-measure/.

2. Export.gov. Taiwan Poultry Meats 2019 [Available from: https://www.export.gov/apex/article2?id=Taiwan-Poultry-Meats.

3. World P. Steady growth for Africa's chicken meat market. 2020.

4. Van Boeckel TP BC, Gilbert M, Grenfell BT, Levin SA, Robinson TP, Teillant A, Laxminarayan R. . Global trends in antimicrobial use in food animals. . Proc Natl Acad Sci U S A. 2015 May 5;112(18):5649-54.

5. Richter CC, Benjamin \& Steele, Jennifer \& Wilcox, Bruce \& Xu, Jianchu. . Intensified food production and correlated risks to human health in the Greater Mekong Subregion: A systematic review. Environmental health : a global access science source 2015.

6. $\quad$ Page SW GP. Use of antimicrobial agents in livestock. Rev Sci Tech. 2012 31(1):145-88.

7. Reig M TF. Veterinary drug residues in meat: Concerns and rapid methods for detection. Meat Sci 2008 78(1-2):60-7.

8. Goetting V LK, Tell LA. . Pharmacokinetics of veterinary drugs in laying hens and residues in eggs: a review of the literature. J Vet Pharmacol Ther. 2011 34(6):521-56.

9. Hedman HD, Vasco, K. A., \& Zhang, L. A Review of Antimicrobial Resistance in Poultry Farming within Low-Resource Settings. Animals : an open access journal from MDPI, . 2020;10(8):1264.

10. Mapiye C. MM, Mupangwa J.F., Chimonyo M., Foti R., Mutenje M.J. A Research Review of Village Chicken Production Constraints and Opportunities in Zimbabwe. Asian-Australasian. J Anim Sci. 2008;21:1680-8. .

11. Vaarst MS, S. \& Horsted, Klaus. Sustainable development perspectives of poultry production. . World's Poultry Science Journal. 2015;71:609-20.

12. Lhermie G. GYT, Raboisson D. Addressing Antimicrobial Resistance: An Overview of Priority Actions to Prevent Suboptimal Antimicrobial Use in Food-Animal Production. Front Microbiol 2017;7

13. R. D. Phenotypic characterization of some indigenous chicken ecotypes of Ethiopia. . Livestock Res Rural Dev. 2017;18.

14. A. W. Poultry bio-security study in Ethiopia. A consultancy report for Food and Agriculture Organization of the United Nations, . 2006.

15. Pagani P WA. Review of the new features of the Ethiopian poultry sector biosecurity implications. Food and Agriculture Organization of the United Nations. FAO2008 [Available from: http://www.fao.org/docrep/013/al837e/al837e00.pdf 
16. Beyene Tea. "Evaluation of rational use of veterinary drugs especially antimicrobials and anthelmintics in Bishoftu, Central Ethiopia.". BMC research notes. 2015;8 (482).

17. Berhe N AB, Abebe N, Tesfaya A, Kalayou S. . Seroprevalence of Salmonella pullorum infection in local and exotic commercial chicken from Mekelle areas, northern Ethiopia. Rev Electrón Vet. 2012;13(9).

18. Theobald S, EMCE, DG, aCA. Antimicrobial Resistance Trends in Escherichia coli in South African Poultry: 2009-2015. Foodborne Pathogens and Disease. 2019;16(9).

19. J-CYeh*C-LChen ${ }^{*}$ C-SChioutD-YLo*J-CCheng*H-CKuo. Comparison of prevalence, phenotype, and antimicrobial resistance of Salmonella serovars isolated from turkeys in Taiwan. Poultry Science. 2018;97(1):279-88.

20. Saharan V, Verma, P, Singh, AP. . Escherichia coli, Salmonella spp., and Staphylococcus aureus susceptibility to antimicrobials of human and veterinary importance in poultry sector of India. J Food Saf. 2020.

21. Penha RACea. Antimicrobial susceptibility of Salmonella Gallinarum and Salmonella Pullorum isolated from ill poultry in Brazil. . Ciência Rural [online] 2016;46(3):513-8.

22. Pribul BR FM, de Souza MM, Rodrigues Ddos P. . Characterization of quinolone resistance in Salmonella spp. isolates from food products and human samples in Brazil. . Braz J Microbiol 2016 47(1):196-201.

23. Penakalapati G SJ, Delahoy MJ, McAliley L, Wodnik B, Levy K, Freeman MC. . Exposure to Animal Feces and Human Health: A Systematic Review and Proposed Research Priorities. . Environ Sci Technol. 2017 51(20):11537-52.

24. Medina-Pizzali ML HS, Salmon-Mulanovich G, Larson A, Riveros M, Mäusezahl D. Antimicrobial Resistance in Rural Settings in Latin America: A Scoping Review with a One Health Lens. . Int J Environ Res Public Health 2021 18(18):9837.

25. Nhung NT, Chansiripornchai N, Carrique-Mas JJ. Antimicrobial Resistance in Bacterial Poultry Pathogens: A Review. Frontiers in Veterinary Science. 2017;4(126).

26. CDC A. One Health Programme

[Available from:

https://africacdc.org/programme/surveillance-disease-intelligence/one-health/.

27. CDC T. Antimicrobial Resistance [Available from:

https://www.cdc.gov.tw/En/Category/ListContent/ P6IYUu810pMdu2FcTPp4g?uaid=BKM8MCw 654j8jE0c1u4eEw.

28. Europe W. Has the European Region embraced the One Health approach in the fight against antimicrobial resistance? 2019 [Available from: https:/www.euro.who.int/en/healthtopics/disease-prevention/antimicrobial-resistance/news/news/2019/11/has-the-european-regionembraced-the-one-health-approach-in-the-fight-against-antimicrobial-resistance.

29. Ranjalkar J CS. India's National Action Plan for antimicrobial resistance - An overview of the context, status, and way ahead. . J Family Med Prim Care. 2019;8(6):1828-34.

30. Oldenkamp R SC, Mancini E, Cappuccio A.. . Filling the gaps in the global prevalence map of clinical antimicrobial resistance. . Proc Natl Acad Sci U S A. 2021 118(1).

31. Criscuolo NG, Pires, J., Zhao, C. et al. resistancebank.org, an open-access repository for surveys of antimicrobial resistance in animals. . Sci Data. 2021. 